\title{
Dynamic mechanical assessment of muscle hyperalgesia in humans: The dynamic algometer
}

\author{
Sara Finocchietti PhD, Thomas Graven-Nielsen PhD DMSc, Lars Arendt-Nielsen PhD DMSc
}

\begin{abstract}
S Finocchietti, T Graven-Nielsen, L Arendt-Nielsen. Dynamic mechanical assessment of muscle hyperalgesia in humans: The dynamic algometer. Pain Res Manag 2015;20(1):29-34.
\end{abstract}

BACKGROUND: Musculoskeletal pain is often associated with a nonhomogeneous distribution of mechanical hyperalgesia. Consequently, new methods able to detect this distribution are needed.

OBJECTIVE: To develop and test a new method for assessing muscle hyperalgesia with high temporal and spatial resolution that provides complementary information compared with information obtained by traditional static pressure algometry.

METHODS: The dynamic pressure algometer was tested bilaterally on the tibialis anterior muscle in 15 healthy subjects and compared with static pressure algometry. The device consisted of a wheel that was rolled over the muscle tissue with a fixed velocity and different predefined forces. The pain threshold force was determined and pain intensity to a fixed-force stimulation was continuously rated on a visual analogue scale while the wheel was rolling over the muscle. The pressure pain sensitivity was evaluated before, during, and after muscle pain and hyperalgesia induced unilaterally by either injection of hypertonic saline $(0.5 \mathrm{~mL}$, $6 \%)$ into the tibialis anterior or eccentric exercise evoking delayed-onset muscle soreness (DOMS).

RESULTS: The intraclass correlation coefficient was $>0.88$ for the dynamic thresholds; thus, the method was reliable. Compared with baseline, both techniques detected hyperalgesia at the saline injection site and during DOMS $(\mathrm{P}<0.05)$. The dynamic algometer also detected the widespread, patchy distribution of sensitive loci during DOMS, which was difficult to evaluate using static pressure algometry.

DISCUSSION AND CONCLUSION: The present study showed that dynamic pressure algometry is a reliable tool for evaluating muscle hyperalgesia (threshold and pain rating) with high temporal and spatial resolution. It can be applied as a simple clinical bed-side test and as a quantitative tool in pharmacological profiling studies.

Key Words: Hyperalgesia; Muscle pain; Pressure assessment

$\mathrm{M}$ usculoskeletal pain is often associated with scattered distribution of tenderness or mechanical hyperalgesia (eg, myofascial trigger points [1]). Generally, pressure hyperalgesia has been observed in many different patient populations (eg, whiplash, fibromyalgia and osteoarthritis [2-4]). Localized experimentally induced muscle hyperalgesia in healthy subjects can be generated by injections of algesic substances (5) and after eccentric exercise inducing delayed-onset muscle soreness (DOMS) (6-8).

The most common tool to assess mechanical hyperalgesia is pressure algometry. A pressure algometer is a force gauge with a well-defined probe area in which the pressure needed to evoke pain can be recorded. Pressure algometry has been used for assessing musculoskeletal hyperalgesia in myofascial pain syndrome, tension-type headache, fibromyalgia and arthritis (9-12), enables the variability related to manual pressure application to be controlled (13), and has

\section{L'évaluation mécanique dynamique de l'hyperalgésie musculaire chez les humains : un algomètre dynamique}

HISTORIQUE : La douleur musculosquelettique s'associe souvent à un répartition non homogène de l'hyperalgésie mécanique. Il faut donc mettre au point de nouvelles méthodes pour déceler cette répartition.

OBJECTIF : Mettre au point et mettre à l'essai une nouvelle méthode pour évaluer l'hyperalgésie musculaire à haute résolution temporelle et spatiale qui fournit de l'information complémentaire par rapport à l'information obtenue par l'algométrie à pression statique classique.

MÉTHODOLOGIE : L'algomètre à pression dynamique a été mis à l'essai bilatéralement sur le muscle tibial antérieur de 15 sujets en santé et comparé à l'algométrie à pression statique. L'appareil était composé d'une roulette passée sur les tissus musculaires à une vélocité fixe, à diverses forces prédéfinies. La force du seuil de douleur était déterminée et l'intensité de la douleur à une stimulation à force fixe était constamment évaluée sur une échelle analogique visuelle lorsque la roulette était passée sur le muscle. La sensibilité à la douleur de pression était évaluée avant, pendant et après la douleur musculaire et l'hyperalgésie induite unilatéralement soit par l'injection d'un soluté physiologique hypertonique $(0,5 \mathrm{~mL}, 6 \%)$ dans le muscle tibial antérieur, soit par l'exercice excentrique évoquant des douleurs musculaires à apparition tardive (DMAT).

RÉSULTATS : Le coefficient de corrélation intraclasse était supérieur à 0,88 pour les seuils dynamiques. La méthode était donc fiable. Par rapport aux données de départ, les deux techniques décelaient l'hyperalgésie au foyer d'injection du soluté physiologique et pendant les DMAT $(\mathrm{P}<0,05)$. L'algomètre dynamique décelait également la répartition inégale généralisée des loci sensibles pendant les DMAT, difficiles à évaluer à l'aide de l'algométrie à pression statique.

EXPOSÉ ET CONCLUSION : La présente étude révèle que l'algométrie de la pression dynamique est un outil fiable pour évaluer l'hyperalgésie musculaire (seuil et classement de la douleur) selon une résolution temporelle et spatiale élevée. On peut l'appliquer à un simple test clinique au chevet du patient et l'utiliser comme outil quantitatif dans des études de profilage pharmacologique.

proven to be a valid and reproducible method (14-17). However, pressure algometry is applied to a localized area and requires many measurements to map sensitivity along a muscle (6) and eventually construct a pressure sensitivity map (18), which is an appropriate pain assessment in multiple clinical conditions. For example, with regard to neuropathic pain, it is well known that dynamic stroking of the skin (eg, by a brush with a given force applied at a given velocity over a distance on the skin $[19,20]$ ) is a way to provoke pain (allodynia) that cannot be assessed by a static stimulus applied to one fixed position. Furthermore, a recent study showed that persistent and constant pain can be caused by the rolling of a $1.75 \mathrm{~kg}$ custom-designed marble roll on the lower leg due to the slow adaptation properties of sensitized nociceptors (21). This study confirms the necessity to develop new tools for more dynamic musculoskeletal pain assessments that provide additional high-resolution temporal and spatial information about the

Laboratory of Musculoskeletal Pain and Motor Control, Center for Sensory-Motor Interaction, Department of Health Science and Technology,

Faculty of Medicine, Aalborg University, Aalborg, Denmark

Correspondence: Dr Lars Arendt-Nielsen, Center for Sensory-Motor Interaction, Department of Health Science and Technology, Faculty of

Medicine, Aalborg University, Fredrik Bajers Vej 7, Bld. D3, DK-9220 Aalborg E, Denmark. Telephone 45-9940-8830,

fax 45-9815-4008, e-mail lan@hst.aau.dk

OPEN $\bigcirc$ ACCESS

This open-access article is distributed under the terms of the Creative Commons Attribution Non-Commercial License (CC BY-NC) (http:// creativecommons.org/licenses/by-nc/4.0/), which permits reuse, distribution and reproduction of the article, provided that the original work is properly cited and the reuse is restricted to noncommercial purposes. For commercial reuse, contact support@pulsus.com 


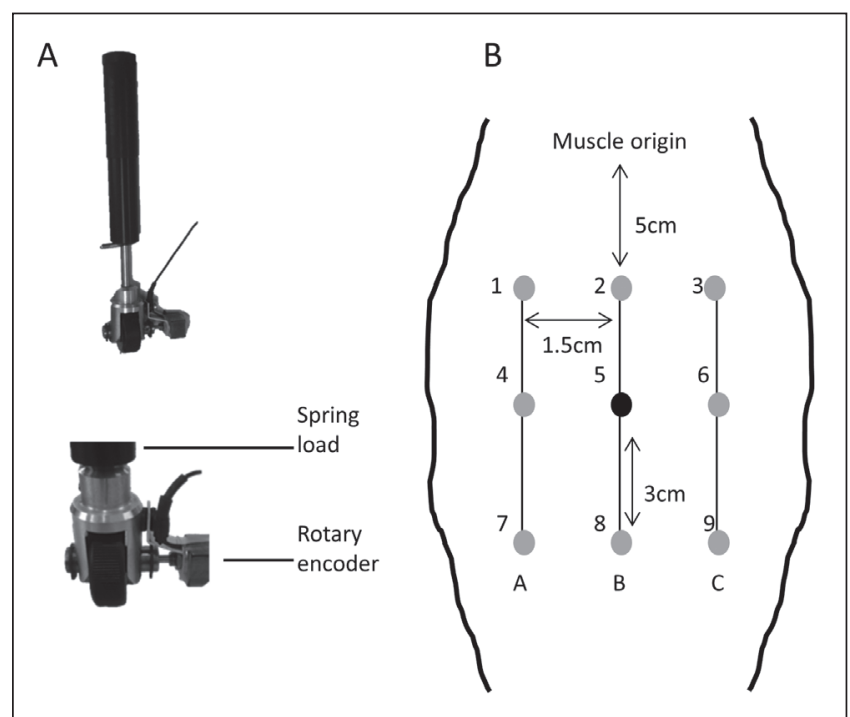

Figure 1) A The dynamic pressure algometer. This device consists of a wheel that applies a specific force determined by a spring within the handle. The experimenter moves the algometer along the desired muscle at a constant velocity of $10 \mathrm{~mm} / \mathrm{s}$. An encoder is attached to the wheel and used to measure the distance (in $\mathrm{cm}$ ) covered during the measurement, while the pain sensitivity is recorded by a electronic visual analogue scale. B Map of the sites for static pressure pain thresholds and dynamic pressure pain thresholds lines evaluated on the tibialis anterior muscle. The point of hypertonic saline injection is indicated in black

manifestations of muscle hyperalgesia. The current study addresses this issue, using the concept of applying a moving pressure stimulus to a musculoskeletal structure in a standardized and quantitative manner.

Consequently, the aims of the present study were: to evaluate a new assessment tool, the dynamic pressure algometer; to compare traditional static versus dynamic pressure algometry; and to apply the novel tool to assess quantitatively experimentally induced muscle hyperalgesia provoked by an exogenous (injection of hypertonic saline) and an endogenous (postexercise muscle soreness) pain model.

\section{Subjects}

\section{METHODS}

Fifteen healthy subjects (age range 23 to 32 years, mean [ \pm SD] body mass index $23.4 \pm 1.1 \mathrm{~kg} / \mathrm{m}^{2}$, eight women) participated in the study. The recruited subjects were all students at Aalborg University (Aalborg, Denmark). The participants had no pain or other medical problems, were not taking any medications and did not engage in any major physical activity two days before the experiment. Written informed consent was obtained from each subject before inclusion in the study. The study was conducted in accordance with the Declaration of Helsinki and approved by the local ethics committee (N-2012-0030).

\section{Dynamic pressure algometry}

The dynamic pressure pain threshold (DPT) was assessed using the dynamic pressure algometer along three lines marked on the tibialis anterior muscle of both legs (Figure 1). The dynamic algometer consisted of a wheel through which the experimenter could apply eight different forces $(450 \mathrm{~g}, 600 \mathrm{~g}, 800 \mathrm{~g}, 1300 \mathrm{~g}, 1500 \mathrm{~g}, 2100 \mathrm{~g}, 3400 \mathrm{~g}$, $5000 \mathrm{~g}$ ) controlled by springs. The wheel had a diameter of $35 \mathrm{~mm}$ and a width of $5 \mathrm{~mm}$. The wheel movement was recorded via a digital encoder (Bournes, USA) with a sensitivity of 64 pulses/revolution to measure the distance covered during the rolling stimulation. The speed of the wheel was visually presented to the experimenter controlling the speed manually to approximately $10 \mathrm{~mm} / \mathrm{s}$.

The wheel was moved on three parallel lines $(6 \mathrm{~cm})$ on the tibialis anterior muscle, with starting points $5 \mathrm{~cm}$ from the origin of the muscle and distance between the lines equal to $1.5 \mathrm{~cm}$ (Figure 1B). The lower weight was used first and increased until the subject perceived a sensation of pain after stimulation of the $6 \mathrm{~cm}$ lines. The assessment was repeated three times. The weight of the wheel, which induced pain for at least two of the three stimuli, was defined as the DPT. After the DPT assessment, the subject continuously scored the pain intensity during rolling stimulation on the three lines with the DPT intensity on an electronic visual analogue scale (VAS) on which $0 \mathrm{~cm}$ indicated 'no pain' and $10 \mathrm{~cm}$ indicated 'maximal pain'. The rolling distance and the VAS scores were sampled at $10 \mathrm{~Hz}$, indicating a measurement step of $0.1 \mathrm{~cm}$. The stimulus-response curve (VAS versus distance) was constructed, and the area under the curve (VAS-distance area) was extracted in MATLAB (Mathworks, USA).

\section{Static pressure algometry}

Pressure stimulation on the nine sites along the tibialis anterior muscle (Figure 1B) was applied perpendicularly to the skin surface by computer-controlled pressure algometry with a mechanical footplate (Aalborg University, Denmark [13]). The pressure stimulation was force controlled, with a force gradient of $0.3 \mathrm{~kg} / \mathrm{s}$ ( $\max$ force $20 \mathrm{~kg}$ ). The subject pressed a button to indicate the pressure pain threshold (PPT). PPT was defined as the point at which a sensation of pressure changed into a sensation of pain. PPT measurements were performed with a $1.0 \mathrm{~cm}^{2}$ probe on all the nine points. For each assessment, the measurement was repeated three times and the mean of these measurements was used in further calculations. An interval of minimum $30 \mathrm{~s}$ was kept between each PPT assessment.

\section{Exogenous muscle hyperalgesia model: Saline-induced pain} Sterile hypertonic saline $(0.5 \mathrm{~mL}, 6 \%)$ was injected intramuscularly into the right tibialis anterior muscle because this is known to induce muscle pain and hyperalgesia (22). The saline was injected into the muscle belly of the tibialis anterior approximately one-third of the distance from the lateral tibial condyle and the talocrural joint, corresponding to point 5 in Figure 1B. Sterile hypertonic saline $(0.5 \mathrm{~mL}$, $6 \%$ ) was injected over approximately $10 \mathrm{~s}$ after the skin had been cleaned with alcohol. The injection was performed using a $2 \mathrm{~mL}$ plastic syringe with a disposable needle $(27 \mathrm{G})$. The pain-intensity profile was monitored by asking the subject to rate the pain using an electronic VAS every $30 \mathrm{~s}$. The scores were between $0 \mathrm{~cm}$ ('no pain') and $10 \mathrm{~cm}$ ('maximal pain'). The maximum VAS score and pain duration were extracted.

\section{Endogenous muscle hyperalgesia model: DOMS}

Three sets of right ankle eccentric plantar flexion were performed with $20 \mathrm{~s}$ rest in between. The subject stood on a $13 \mathrm{~cm}$ high metal platform with the heel of the right leg on the edge of the platform with the midand forefoot extending over the edge (8). The palms of the subject were placed on the wall at shoulder level for support only. The subject performed a slow plantar flexion of the ankle allowing the forefoot to descend until the toes touched a soft foam cushion $(2 \mathrm{~cm}$ thick $)$ placed below the platform. Then the subject returned to the initial starting position (7). Subjects repeated this process 20 times per set. A sevenpoint Likert scale was used to assess soreness $(1=$ no soreness; $7=$ unbearable soreness) one day after the exercise (23).

\section{Protocol}

The experiment was performed on two consecutive days. On the first day, the origin of the tibialis anterior muscle was located by palpation on both legs. DPTs and PPTs at baseline were measured. Exogenous muscle hyperalgesia was then induced by saline injection into the right tibialis anterior muscle, and DPTs and PPTs were remeasured $5 \mathrm{~min}$ after pain had disappeared (approximately $15 \mathrm{~min}$ after injection). Pilot experiments had shown that it was not possible to evaluate pain due to dynamic stimulation during the hypertonic saline effect because subjects were not able to distinguish between the pain due to the injection and the pain due to the stimulation per se. Following the assessments after saline-induced muscle pain, there was a 10 min break with complete rest. After the rest, the subject performed eccentric 


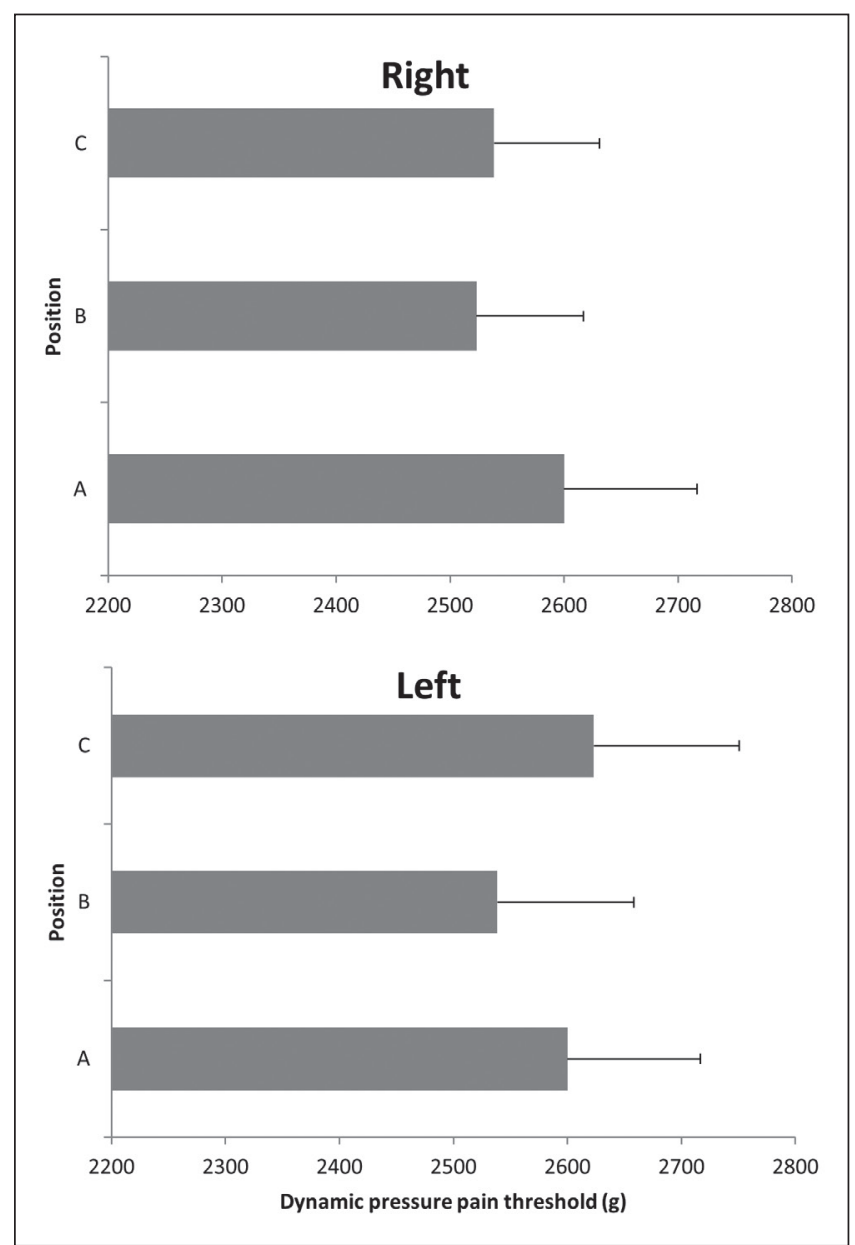

Figure 2) Mean ( $\pm S E)$ dynamic pressure threshold $(g)$ on the three lines evaluated

exercise with the right tibialis anterior muscle to induce DOMS. On the second day, the pain sensitivity was monitored bilaterally using the same methods as at baseline of day 1 .

\section{Data analysis and statistics}

The data are presented as means and SEM. All analyses were performed using STATISTICA (StatSoft Inc, USA). Based on previous studies with similar parameters reflecting the pressure pain sensitivity $(24,25)$, approximately 15 participants were sufficient to assess the method's validity in the current study design.

Data passed the Kolmogorov-Smirnov test for normal distribution. The baseline DPTs were analyzed using a two-way repeated-measures ANOVA (RM-ANOVA) with the factors leg (left and right) and position (lines A, B, C). The VAS-distance area was analyzed using a three-way RM-ANOVA with the factors pain paradigm (baseline, injection, DOMS), leg (left and right) and position (lines A, B, C). PPTs were analyzed using a three-way RM-ANOVA with the factors pain paradigm (baseline, injection, DOMS), leg (left and right) and points (1 to 9). The Neuman-Keuls (NK) post hoc test was used when factors were significant. A Pearson's correlation analysis was used to assess relationships among PPTs and the corresponding VAS score from rolling stimulation at the same point in the experimental pain paradigm. The intrarater reliability was tested using a two-way mixed intraclass correlation coefficient (ICC) with absolute agreement (2.1), comparing the DPTs and VAS-distance area on leg and position. The results were interpreted according to established grading criteria: $\mathrm{ICC}<0.20=$ poor, 0.21 to $0.40=$ fair, 0.41 to $0.60=$ moderate, 0.61 to $0.80=\operatorname{good}$ and 0.81 to $1.00=$ very $\operatorname{good}(26)$. The

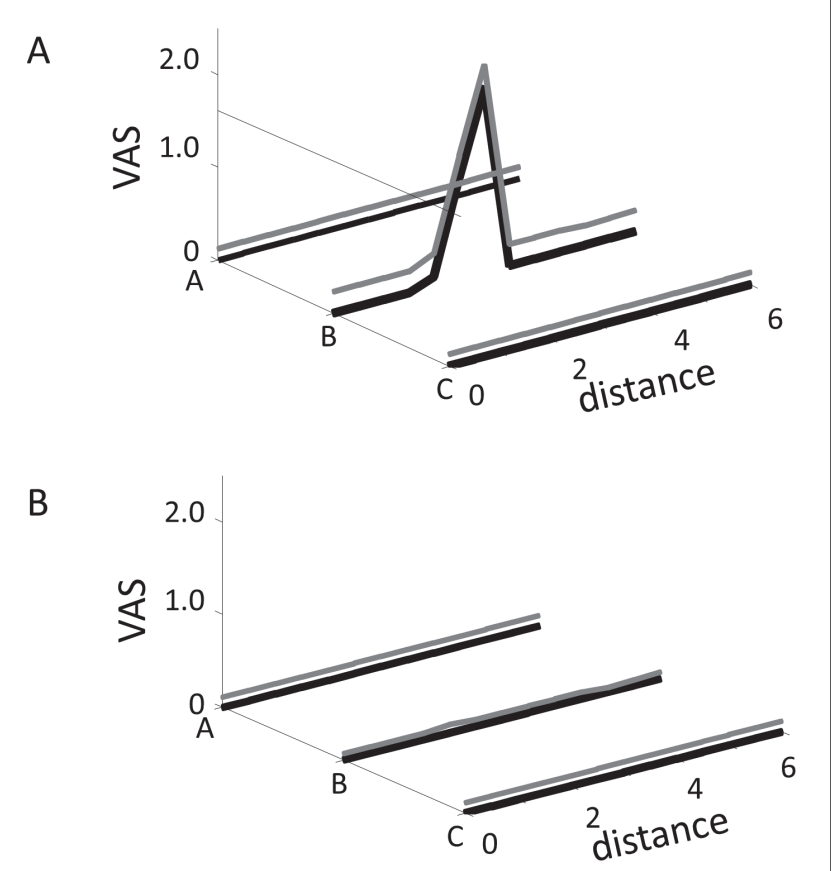

Figure 3) Mean visual analogue scale scores $(\mathrm{cm})$ versus distance $(\mathrm{cm})$ profile after saline-induced muscle hyperalgesia in the tibialis anterior muscle of the experimental muscle pain leg (A) and control leg (B). The rolling stimulation assessment on the lines A, B and C is illustrated with black lines. The grey line related to each curve indicates the SD

sensitivity distribution was mapped, indicating a $15 \%$ pain sensitivity increase or decrease compared with baseline. $\mathrm{P}<0.05$ was considered to be statistically significant.

\section{DPTs}

\section{RESULTS}

The DPTs detected at baseline were not significantly different, regardless of the leg or the assessment line being evaluated (Figure 2). For the left leg, mean $( \pm$ SE) DPT values of $2.30 \pm 0.11 \mathrm{~kg}, 2.28 \pm 0.11 \mathrm{~kg}$ and $2.36 \pm 0.10 \mathrm{~kg}$ were observed for lines A, B and C, respectively. Similarly, for the right leg, mean DPT values of $2.58 \pm 0.12 \mathrm{~kg}$, $2.54 \pm 0.12 \mathrm{~kg}$ and $2.62 \pm 0.13 \mathrm{~kg}$ were observed for lines A, B and C, respectively. The ICC coefficient was 0.88 for both legs.

\section{Saline-induced muscle pain and DOMS}

The maximum VAS score after injection of hypertonic saline was $7.6 \pm 2 \mathrm{~cm}$ and the pain duration was $450 \pm 60 \mathrm{~s}$. All participants subjected to saline-induced muscle pain experienced local pain and two subjects reported that the pain referred to the corresponding ankle (data not shown). The Likert scale indicated that all the subjects developed DOMS one day after the eccentric exercise, with a mean score of $2.1 \pm 0.9$.

Dynamic pressure algometry after induction of experimental muscle hyperalgesia

Before saline-induced pain, the VAS-distance area was, on average, $0.004 \pm 0.003 \mathrm{~cm}^{2}$ during rolling mechanical stimulation with an intensity equal to the DPT level. The peak VAS during rolling mechanical stimulation was $2.2 \pm 0.2 \mathrm{~cm}$ at a position corresponding to the injection site of hypertonic saline (Figure 3). ANOVA of the VAS-distance area demonstrated a significant interaction among pain paradigm, leg and line position $\left(\mathrm{F}_{4}=9.1, \mathrm{P}<0.01\right)$. Five minutes post-pain, the VASdistance area corresponding to the line of the injection site on the right leg was significantly higher compared with the other two lines and with the other leg $(\mathrm{NK}: \mathrm{P}<0.03)$. 


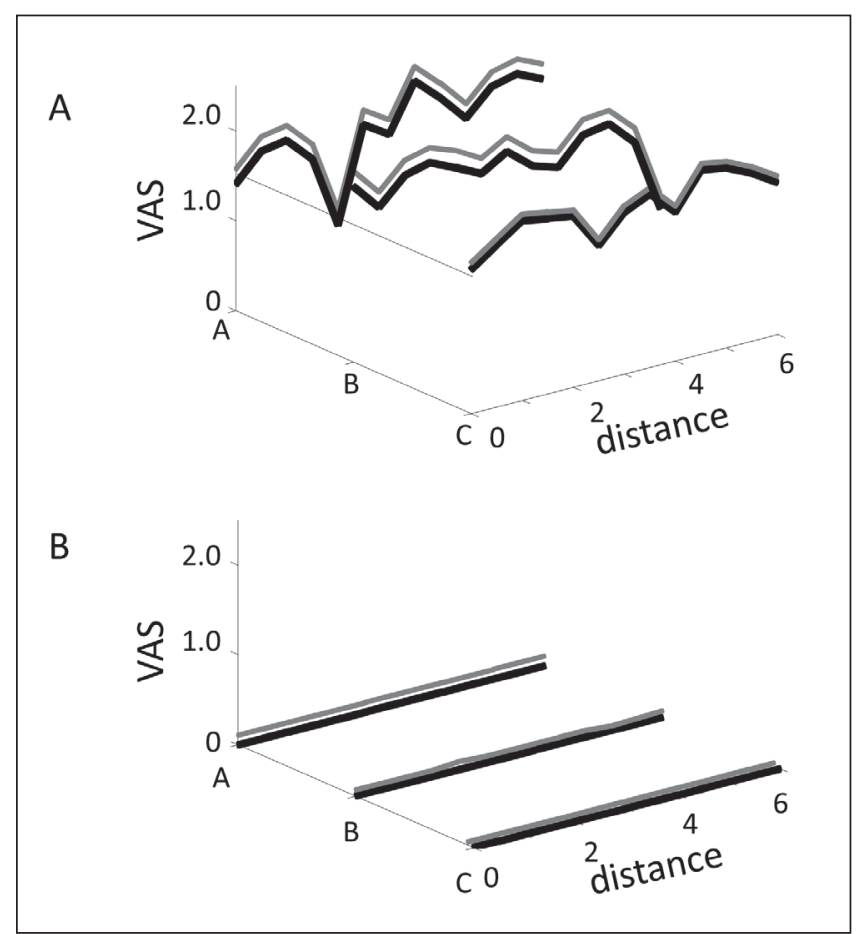

Figure 4) Mean visual analogue scale score $(\mathrm{cm})$ versus distance $(\mathrm{cm})$ profile $24 \mathrm{~h}$ after eccentric exercise when delayed post-exercise soreness has developed (A) and in the control leg (B). The rolling stimulation assessment on the lines A, B and C is illustrated with black lines. The grey line related to each curve indicates the SE

The VAS peak at the dynamic pressure threshold on the DOMS leg was $2.0 \pm 0.4 \mathrm{~cm}$ over the muscle belly (line $\mathrm{B}$, distance $3 \mathrm{~cm}$ equivalent to point 5) while no pain was felt on the unaffected leg (Figure 4A and 4B). The VAS-distance area one day after eccentric exercise showed a significant increase in the response from the DOMS leg compared with the corresponding area at baseline, regardless of the line of stimulation $(\mathrm{NK}: \mathrm{P}<0.01)$.

\section{Static PPTs}

The ANOVA of PPTs showed a significant interaction among pain paradigm, leg and assessment site $\left(\mathrm{F}_{16}=15.6 ; \mathrm{P}<0.05\right)$. The PPT obtained $5 \mathrm{~min}$ after saline-induced pain at the injection site was significantly decreased compared with the measurement at baseline and on the other leg $(\mathrm{NK}: \mathrm{P}<0.03$; Figure 5$)$. The PPTs obtained after DOMS were significantly lower than the PPTs at baseline or on the unexercised leg, regardless of the point of stimulation (NK: $\mathrm{P}<0.05$; Figure 5).

At baseline, the VAS score after rolling stimulation meaured at the sites for PPT assessments correlated with the PPTs for all nine points $(\mathrm{R}=0.86, \mathrm{P}<0.05)$. Five minutes after saline-induced pain, the most sensitive site was point 5 (the muscle belly) while the least sensitive site was point 9 (the most distal point from the tibial tuberosity). In the DOMS leg, PPTs and corresponding VAS scores after rolling stimulation did not correlate for any assessment points $(P>0.10)$. The most sensitive site was point 5 for both the pressure algometry (Figure 6) and dynamic algometry (Figure 7) assessments. However, the VAS related to dynamic pain assessment showed the presence of sensitive loci, nonvisible with the pressure algometry measurement (Figure 7).

\section{DISCUSSION}

The current study demonstrated that dynamic pressure algometry is a useful easy-to-use and reliable tool for quantitative evaluation of temporal and spatial aspects of dynamic muscle hyperalgesia (pain threshold and evoked pain ratings).

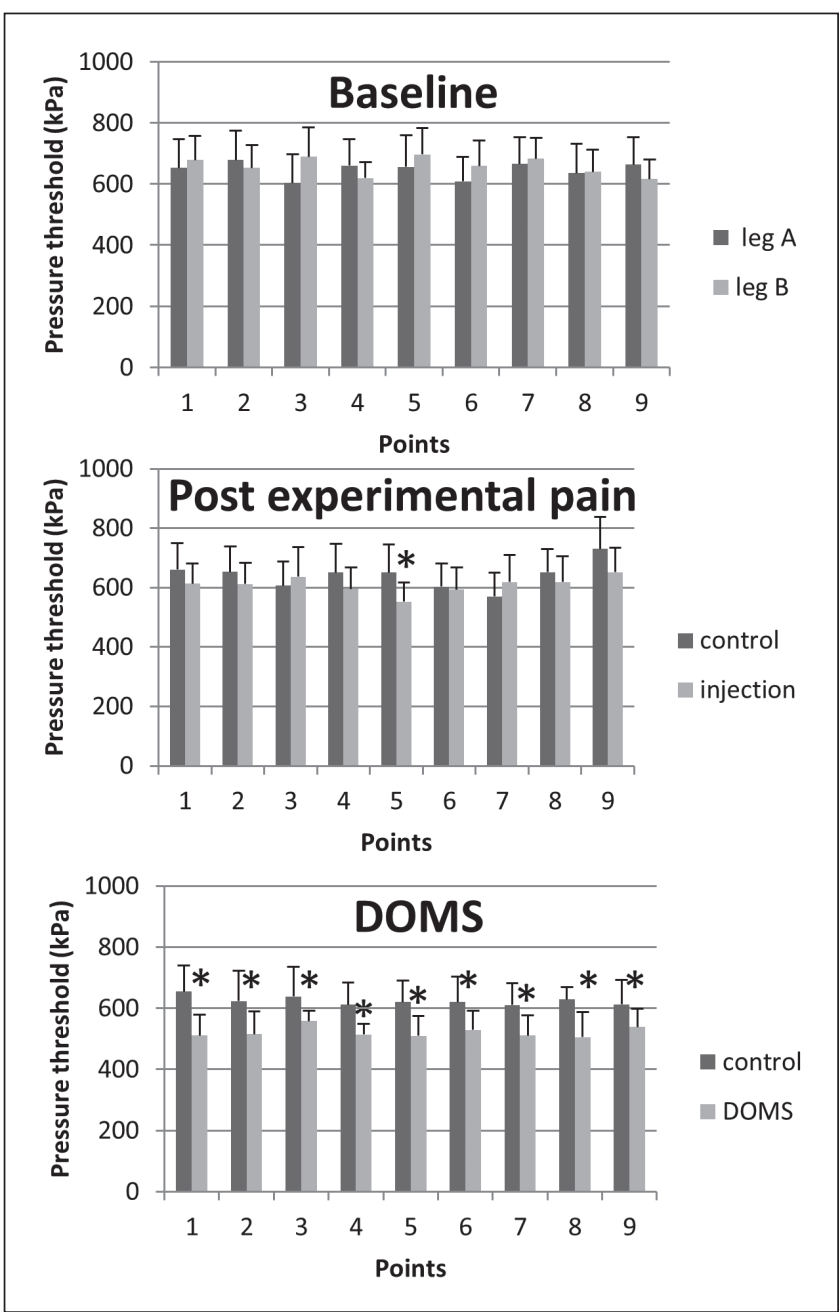

Figure 5) Mean ( \pm SE) pressure pain thresholds $(n=15)$ assessed by the computer-controlled pressure algometer of the nine points assessed on the tibialis anterior muscle at baseline (A), 5 min post-saline-induced pain (B), and $24 \mathrm{~h}$ after eccentric exercise (delayed-onset muscle soreness [DOMS]) (C). Significant differences between legs and baseline are indicated $(* P<0.05)$

Dynamic mechanical pressure algometry

Standardized mechanical stimulation of musculoskeletal tissues is a common method for excitation of nociceptors $(13,27)$. The dynamic pressure algometer showed good reliability in both pain thresholds and pain ratings, with interclass correlation coefficients of 0.75 to 0.88 . Previous studies using the static handheld pressure algometry technique showed poor reliability (28).

The PPTs assessed by static pressure algometry vary substantially and depend on the stimulus configuration parameters such as application rate and area $(14,15,29)$. Dynamic pressure algometry differs from static pressure algometry in the volume of tissue stimulated and, hence, the dynamic technique may mimic the way cutaneous allodynia is assessed. In addition, it enables measurement of the spatial distribution of hypersensitive loci along a muscle structure in one assessment session. This is a common phenomenon in multiple experimental and clinical evaluations $(30,31)$. However, the evaluation of these hypersensitive loci to construct pressure sensitivity maps (ie, Binderup et al [18]) is very time consuming if performed with static pressure algometry. In addition, the spatial and temporal aspects of hypersensitivity are included in the assessment using the dynamic algometry. In many neuropathic pain conditions, dynamic tactile allodynia is a common feature that can only be provoked by stroking the skin. This feature should be similarly assumed for deep somatic tissues, and the dynamic algometer may be useful for 


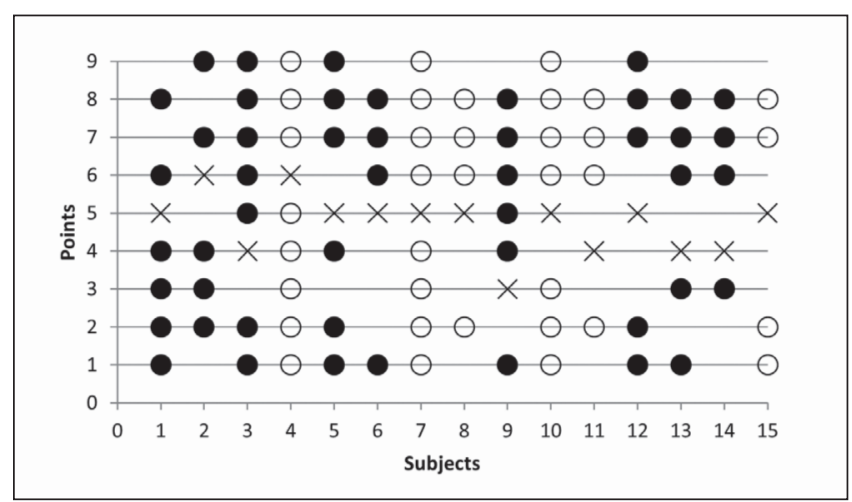

Figure 6) Distribution of pressure pain threshold $(n=15)$ changes assessed by the computer-controlled pressure algometer at the nine sites on the tibialis anterior muscle during delayed-onset muscle soreness. Open circles represent decreased sensitivity (15\% increase of pressure pain threshold compared with baseline) and filled circles represent increased sensitivity (15\% reduction of pressure pain threshold compared with baseline) $\times$ indicates the site of maximal sensitivity (ie, the pressure pain threshold with the largest reduction) for each subject

assessing this. Assessing dynamic versus static cutaneous hypersensitivity in neuropathic pain shows differentiated patterns in different patient populations (32). To date, this aspect has not been addressed for deeper tissues, and the present technique may be used for such assessments. Further clinical studies are needed to investigate possible differentiated responses to static and dynamic pressure algometry in groups of patients with chronic musculoskeletal pain problems, and to determine whether different analgesics modulate the two responses differently.

\section{Dynamic pressure algometry after hypertonic saline}

The hypertonic saline model has been used extensively to characterize the sensory and motor effects involved in muscle pain because the quality of the induced pain is comparable with acute clinical muscle pain and causes a dominant sensation of deep, diffuse pain with referred pain characteristics $(14,33)$. The changes in the evoked somatosensory changes after experimental saline-induced pain are complex. Five minutes after saline-induced muscle pain, hyperalgesia to pressure was found $2 \mathrm{~cm}$ to $10 \mathrm{~cm}$ from the injection site, although it was not uniformly distributed $(34,35)$. In addition, Qerama et al (36) observed decreases in PPTs at the injection site after the saline-induced pain had disappeared. In the present study, the stimulus response curve during dynamic algometry showed a peak in pain sensitivity at the point injected with hypertonic saline. This is in accordance with previous studies in which the injection site showed increased pain sensitivity $5 \mathrm{~min}$ after pain had disappeared (35). The other parts of the muscle and the other leg did not show hyperalgesia, in accordance with a previous study (22).

\section{Dynamic pressure algometry after eccentric exercise}

Eccentric exercise is a widely used method of endogenous pain induction in humans. Following this type of exercise, DOMS over the muscle tissue is present after $24 \mathrm{~h}$ to $48 \mathrm{~h} \mathrm{(37),} \mathrm{allowing} \mathrm{investigation}$ of muscle hyperalgesia to be undertaken in this period. The mechanism underlying DOMS is likely related to ultrastructural tissue damage

\section{REFERENCES}

1. Simons DG, Travell JG, Simons LS. Travell \& Simons' Myofascial Pain and Dysfunction: The Trigger Point Manual. Williams \& Wilkins, 1999;2:21-2.

2. Koelbaek JM, Graven-Nielsen T, Schou OA, Arendt-Nielsen L. Generalised muscular hyperalgesia in chronic whiplash syndrome. Pain 1999;83:229-34.

3. Bennett RM. The rational management of fibromyalgia patients. Rheum Dis Clin North Am 2002;28:181-200.

4. Arendt-Nielsen L, Nie H, Laursen MB, et al. Sensitization in patients with painful knee osteoarthritis. Pain 2010;59:235-9.

5. Andersen H, Arendt-Nielsen L, Svensson P, Danneskiold-Samsøe B, Graven-Nielsen T. Spatial and temporal aspects of muscle

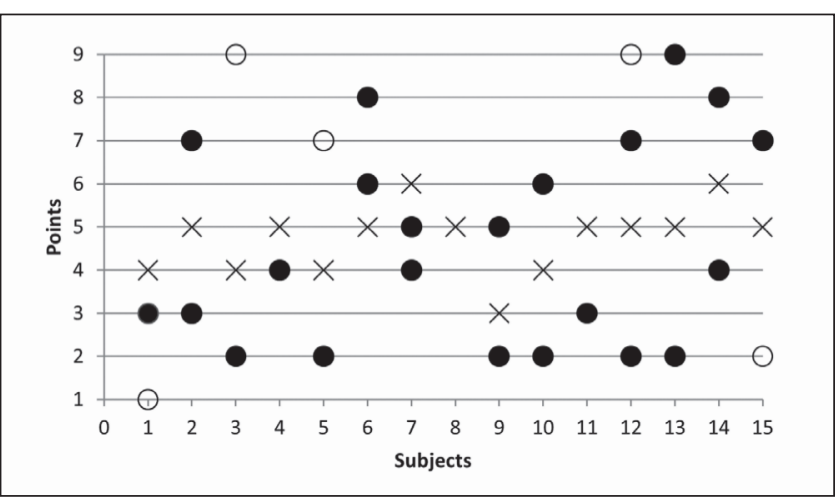

Figure 7) Distribution of pain sensitivity (visual analogue scale scores at the corresponding assessment site $[n=15]$ ) at the nine sites along the tibialis anterior muscle during delayed-onset muscle soreness. Open circles represent increased sensitivity (+15\% compared with baseline) and filled circles represent decreased sensitivity ( $-15 \%$ compared with baseline). $\times$ indicates the site of maximal sensitivity (ie, the visual analogue scale score with the largest increase) for each subject

resulting in the release of algesic substances in the muscle and localized inflammatory processes (38).

Eccentric exercise is traditionally used to induce DOMS and can be utilized in both upper and lower limb muscles $(30,39)$. Mechanical hyperalgesia is a hallmark of DOMS but is not evenly distributed over the affected muscle (8). The most commonly reported site of tenderness in DOMS is the mid-muscle belly region $(30,39)$. Andersen et al $(6)$ showed significantly decreased PPTs for muscle belly sites. Some variations in the spatial expression of hyperalgesia were found among test sites. In the present study, the site of hyperalgesia assessed by dynamic pressure algometry was spread along the tibialis anterior muscle, consistent with previous studies $(6,8)$. While the muscle belly was a common site of maximal sensitivity, there was considerable variation in the spatial distribution among subjects. A widespread, patchy distribution of sensitive loci during DOMS has previously been demonstrated (30).

\section{CONCLUSION}

The developed dynamic pressure algometry is a new reliable and quantitative method for evaluating muscle hyperalgesia with high temporal and spatial resolution. This tool may provide complementary information compared with information achieved by traditional static pressure algometry. This method is easy to use as a clinical bedside test for examining patients with musculoskeletal pain and associated musculoskeletal hypersensitivity. The technique may also be used as a tool in pharmacological profiling studies. Further clinical studies are needed to investigate the diagnostic validity of possible differentiating responses to static and dynamic pressure algometry in different patient populations.

ACKNOWLEDGEMENTS: The authors thank Thorvaldur S Palsson and Steffan W Christensen for their support during the experimental procedure. This study was supported by the Shionogi Science Program and the Danish National Advanced Technology Foundation. The authors have no conflict of interest to declare.

hyperalgesia induced by nerve growth factor in humans. Exp Brain Res 2008;191:371-82.

6. Andersen H, Arendt-Nielsen L, Danneskiold-Samsøe B, Graven-Nielsen T. Pressure pain sensitivity and hardness along human normal and sensitized muscle. Somatosens Mot Res 2006;23:97-109.

7. Gibson W, Arendt-Nielsen L, Graven-Nielsen T. Referred pain and hyperalgesia in human tendon and muscle belly tissue. Pain 2006;120:113-23.

8. Gibson W, Arendt-Nielsen L, Taguchi T, Mizumura K, Graven-Nielsen T. Increased pain from muscle fascia following eccentric exercise: Animal and human findings. Exp Brain Res 2009;194:299-308. 
9. Vanderweeen L, Oostendorp RA, Vaes P, Duquet W. Pressure algometry in manual therapy. Man Ther 1996;1:258-65.

10. Langemark M, Jensen K, Jensen TS, Olesen J. Pressure pain thresholds and thermal nociceptive thresholds in chronic tension-type headache. Pain 1989;38:203-10.

11. Gerecz-Simon EM, Tunks ER, Heale JA, Kean WF, Buchanan WW. Measurement of pain threshold in patients with rheumatoid arthritis, osteoarthritis, ankylosing spondylitis, and healthy controls. Clin Rheumatol 1989;8:467-74.

12. Carli G, Suman AL, Biasi G, Marcolongo R. Reactivity to superficial and deep stimuli in patients with chronic musculoskeletal pain. Pain 2002;100:259-69.

13. Graven-Nielsen T, Mense S, Arendt-Nielsen L. Painful and non-painful pressure sensations from human skeletal muscle. Exp Brain Res 2004;159:273-83.

14. Jensen R, Rasmussen BK, Pedersen B, Lous I, Olesen J. Cephalic muscle tenderness and pressure pain threshold in a general population. Pain 1992;48:197-203.

15. Kosek E, Ekholm J, Nordemar R. A comparison of pressure pain thresholds in different tissues and body regions. Long-term reliability of pressure algometry in healthy volunteers. Scand J Rehabil Med 1993;25:117-24.

16. Isselée H, Laat A, Lesaffre E, Lysens R. Short-term reproducibility of pressure pain thresholds in masseter and temporalis muscles of symptom-free subjects. Eur J Oral Sci 1997;105:583-7.

17. Brennan TJ, Vandermeulen EP, Gebhart GF. Characterization of a rat model of incisional pain. Pain 1996;64:493-501.

18. Binderup A, Arendt-Nielsen L, Madeleine P. Pressure pain sensitivity maps of the neck-shoulder and the low back regions in men and women. BMC Musculoskel Disord 2010;11:234-41.

19. du Jardin KG, Gregersen LS, Røsland T, et al. Assessment of pain response in capsaicin-induced dynamic mechanical allodynia using a novel and fully automated brushing device. Pain Res 2012;18:6-10.

20. Samuelssonl M, Lefflerl A, Johanssonl B, Hanssonl P. The influence of brushing force and stroking velocity on dynamic mechanical allodynia in patients with peripheral neuropathy. Eur J Pain 2011;15:389-94.

21. Zimmermann K, Leidl C, Kaschka M, et al. Central projection of pain arising from delayed onset muscle soreness (DOMS) in human subjects. PLoS One 2012;7:e47230.

22. Graven-Nielsen T, Arendt-Nielsen L, Svensson P, Jensen TS. Experimental muscle pain: A quantitative study of local and referred pain in humans following injection of hypertonic saline. J Musculoskelet Pain 1997;5:49-69.

23. Smith LL, Brunetz MH, Chenier TC, et al. The effects of static and ballistic stretching on delayed onset muscle soreness and creatine kinase. Res Q Exerc Sport 1993;64:103-7.
24. Finocchietti S, Nielsen M, Mørch CD, Arendt-Nielsen L, Graven-Nielsen T. Pressure-induced muscle pain and tissue biomechanics: A computational and experimental study. Eur J Pain 2011;15:36-44.

25. Nie H, Arendt-Nielsen L, Andersen H, Graven-Nielsen T. Temporal summation of pain evoked by mechanical stimulation in deep and superficial tissue. J Pain 2005;6:348-55.

26. Portney LG, Watkins MP. Foundations of Clinical Research. Upper Saddle River: Pearson/Prentice Hall, 1993.

27. Polianskis R, Graven-Nielsen T, Arendt-Nielsen L. Pressure-pain function in desensitized and hypersensitized muscle and skin assessed by cuff algometry. J Pain 2002;3:28-37.

28. Ohrbach R, Gale EN. Pressure pain thresholds, clinical assessment, and differential diagnosis: Reliability and validity in patients with myogenic pain. Pain 1989;39:157-69.

29. Brennum J, Kjeldsen M, Jensen K, Jensen TS. Measurements of human pressure-pain thresholds on fingers and toes. Pain (Amsterdam) 1989;38:211-7.

30. Weerakkody N, Percival P, Hickey M, et al. Effects of local pressure and vibration on muscle pain from eccentric exercise and hypertonic saline. Pain 2003;105:425-35.

31. Hong CZ. Algometry in evaluation of trigger points and referred pain. J Musculoskeletal Pain 1998;6:47-60.

32. Maier C, Baron R, Tölle T, et al. Quantitative sensory testing in the German Research Network on Neuropathic Pain (DFNS): Somatosensory abnormalities in 1236 patients with different neuropathic pain syndromes. Pain 2010;150:439-50.

33. Svensson P, Arendt-Nielsen L, Nielsen H, Larsen JK. Effect of chronic and experimental jaw muscle pain on pain-pressure thresholds and stimulus-response curves. J Orofac Pain 1995;9:347.

34. Vecchiet L, Dragani L, De Bigontina P, Obletter G, Giamberardino M. Experimental referred pain and hyperalgesia from muscles in humans. Pain Res Clin Manag 1993;7:239-49.

35. Graven-Nielsen T, Arendt-Nielsen L, Svensson P, Staehelin Jensen T. Quantification of local and referred muscle pain in humans after sequential im injections of hypertonic saline. Pain 1997;69:111-7.

36. Qerama E, Fuglsang-Frederiksen A, Kasch H, Bach FW, Jensen TS. Evoked pain in the motor endplate region of the brachial biceps muscle: An experimental study. Muscle Nerve 2004;29:393-400.

37. Newham D. The consequences of eccentric contractions and their relationship to delayed onset muscle pain. Eur J Appl Physiol Occup Physiol 1988;57:353-9.

38. Kumazawa T, Mizumura K. Thin-fibre receptors responding to mechanical, chemical, and thermal stimulation in the skeletal muscle of the dog. J Physiol 1977;273:179.

39. Slater H, Arendt-Nielsen L, Wright A, Graven-Nielsen T. Experimental deep tissue pain in wrist extensors - a model of lateral epicondylalgia. Eur J Pain 2003;7:277-88. 


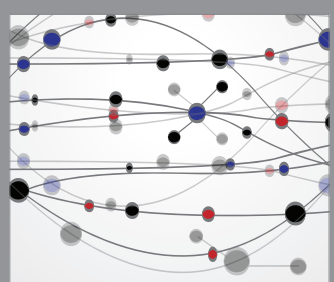

The Scientific World Journal
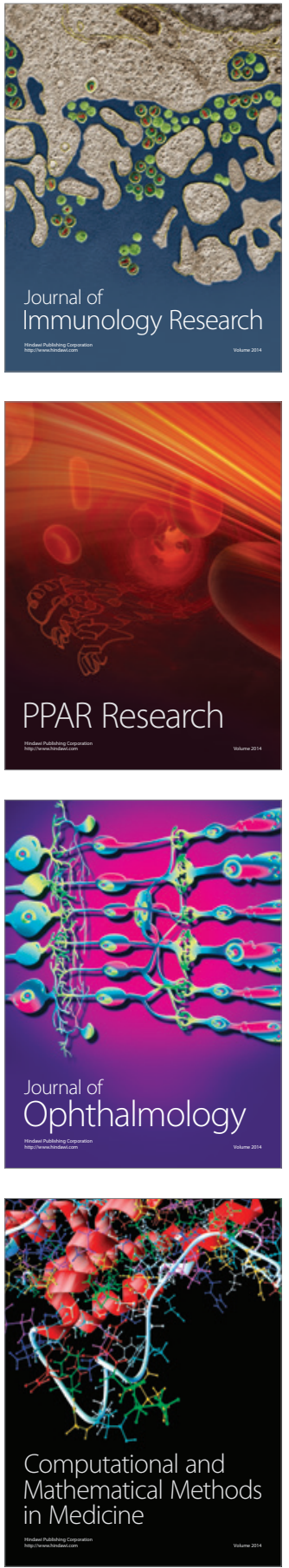

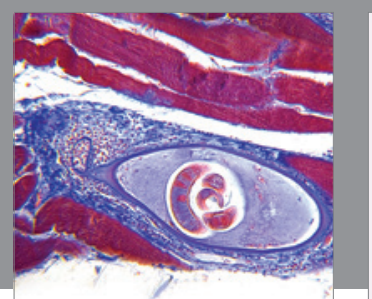

Gastroenterology Research and Practice

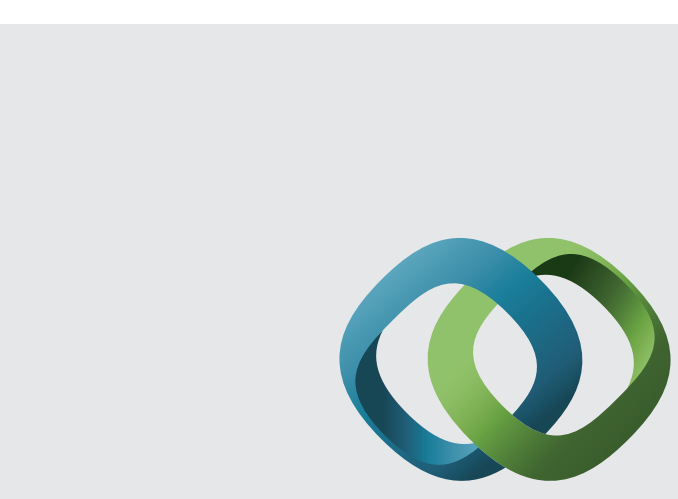

\section{Hindawi}

Submit your manuscripts at

http://www.hindawi.com
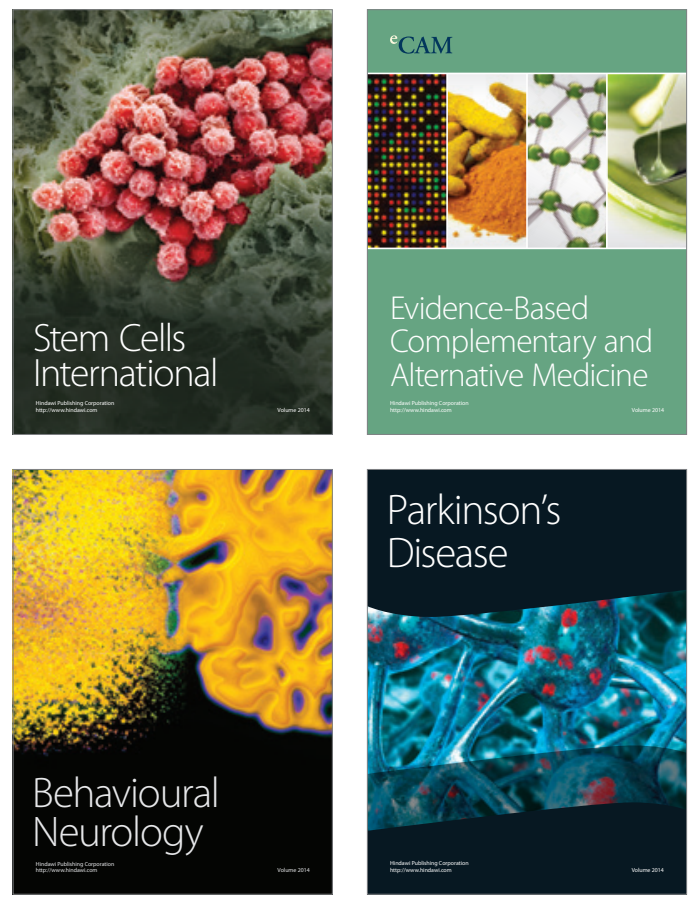
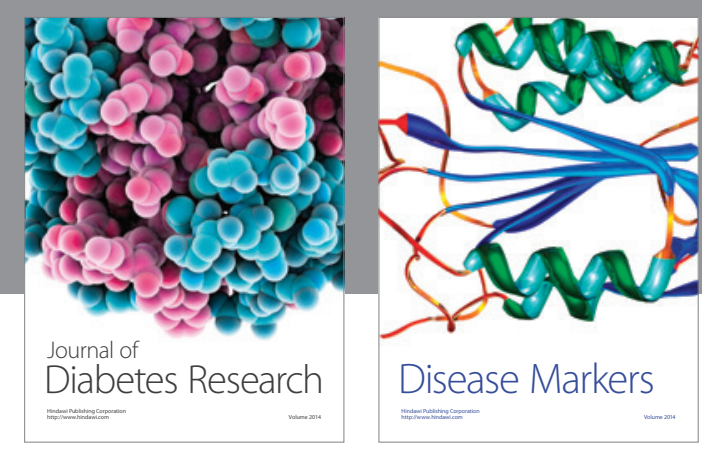

Disease Markers
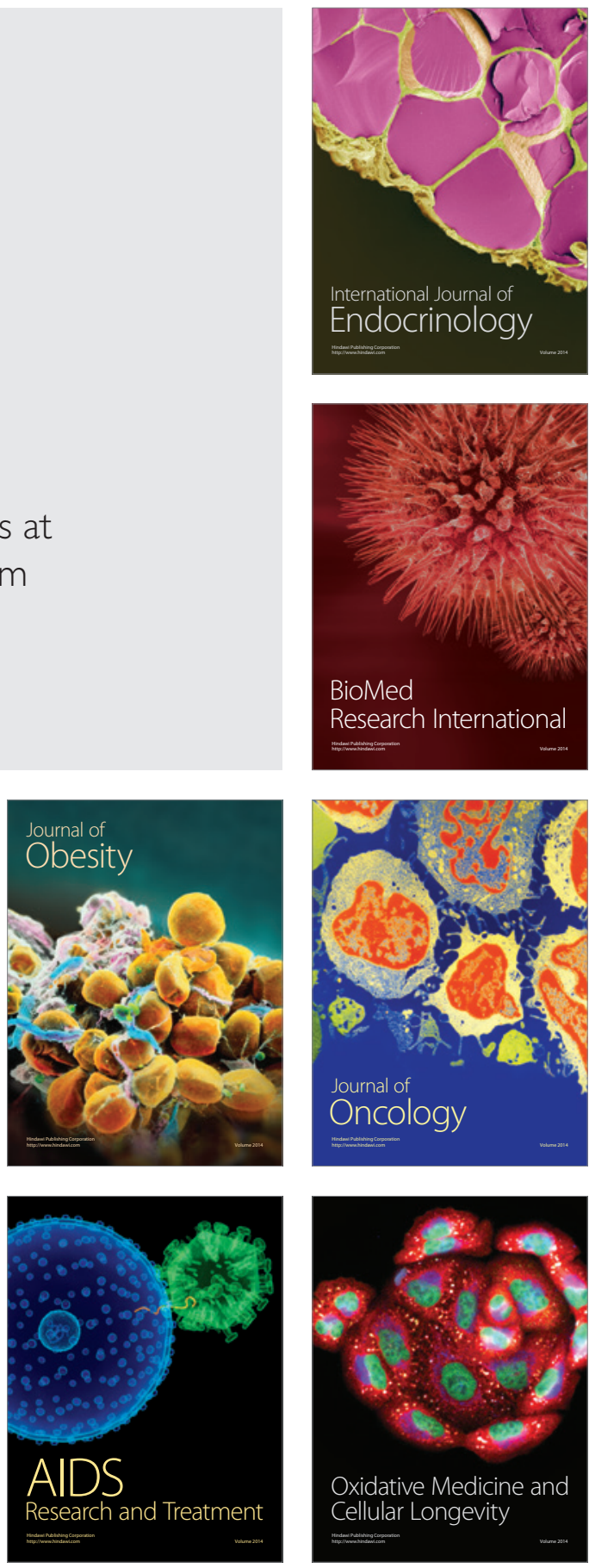